Article

\title{
Physical and Mechanical Characterization of Sustainable and Innovative Porous Concrete for Urban Pavements Containing Metakaolin
}

\author{
Eduardo-Javier Elizondo-Martinez ${ }^{1, *(\mathbb{C})}$, Piergiorgio Tataranni ${ }^{2, *} \mathbb{C}^{\text {, }}$ \\ Jorge Rodriguez-Hernandez ${ }^{1}(\mathbb{D})$ and Daniel Castro-Fresno ${ }^{1}(\mathbb{D}$ \\ 1 GITECO Research Group, Universidad de Cantabria, Avda de los Castros s/n, 39005 Santander, Spain; \\ rodrighj@unican.es (J.R.-H.); castrod@unican.es (D.C.-F.) \\ 2 DICAM Department, University of Bologna, Via Terracini 28, 40131 Bologna, Italy \\ * Correspondence: eduardo-javier.elizondo@alumnos.unican.es (E.-J.E.-M.); \\ piergiorg.tataranni2@unibo.it (P.T.)
}

Received: 6 May 2020; Accepted: 20 May 2020; Published: 21 May 2020

check for updates

\begin{abstract}
Alternative materials to replace cement in pavements have recently been widely studied with the purpose of decreasing the environmental impacts that the construction industry generates. In this context, the implementation of sustainable urban drainage systems has grown, especially with porous pavements, with the intention to reduce water and environmental impacts. In the present investigation, the addition of alternative materials to minimize the use of cement in porous concrete pavements is evaluated. Starting from a partial substitution of Portland cement with metakaolin, experimental geopolymer concretes were produced with metakaolin and waste basalt powder according to several dosages. Two sets of mixtures were analyzed to evaluate the Porous Concrete Design (PCD) methodology for porous concrete mixtures with alternative materials. A deep analysis was proposed for the evaluation of the mechanical and volumetric properties of the mixtures. Results demonstrated that replacing $5 \%$ of cement with metakaolin can increase both permeability and indirect tensile strength. Geopolymer mixtures can achieve permeability significantly higher than the traditional porous concrete, but this decreases their indirect tensile strength. However, considering the promising results, an adjustment in the mix design of the geopolymer mixtures could increase their mechanical properties without negatively affecting the porosity, making these materials a suitable alternative to traditional porous cement concrete, and a solution to be used in urban pavements.
\end{abstract}

Keywords: porous concrete; metakaolin; geopolymers; permeable pavements; urban drainage systems

\section{Introduction}

Sustainable solutions are the main issue for researchers in the construction industry, this sector being responsible for $36 \%$ of global energy use and $40 \%$ of $\mathrm{CO}_{2}$ emissions [1]. Pavements have gained considerable attention due to the impact they are causing, and the environmental benefits they can provide. By the early 2000s, around 3\% of the total surface of the planet had been covered with pavements [2]. This brings many problems, such as the obstruction of the hydrological cycle, causing runoff and water pollution [3], and the increase of temperatures in urban areas due to the solar absorption of the pavements (Urban Heat Island, UHI) [2]. This high amount of pavement is also related to the use of motor vehicles, generating gas emissions into the air [4].

In this context, the concept of Sustainable Urban Drainage Systems (SUDS) has come up to deal with storm water management. Porous pavements are the most widely used type of SUDS that can, 
with a proper design, deal with the UHI effect and the air pollution, as well [4]. The most common materials employed in porous pavements are asphalt and cement concretes. The latter is recognized as a good solution to reduce both water and temperature environmental impacts [3] and has several advantages in the construction operations if compared to porous asphalt. The problem with the minor use of porous pavements remains in their structure, designed to maintain a high porosity, around 15-30\% [5-7], which leads to a low load-bearing capacity that limits its ability to resist under traffic loads [8,9]. In addition, the energy and greenhouse gas emissions required for processing Portland cement are very high in comparison with other materials [10], although asphalt pavements have a greater impact on the environment because of the greenhouse gas emissions generated during the manufacturing of raw materials and the need of disposing the pavement in hazardous waste management facilities [11].

Thus, alternative materials have been recently studied to partially or totally replace the cement from porous concrete and obtain a more eco-friendly pavement. This is the case of geopolymer development [12-14], in which the use of specific powders (e.g., metakaolin, fly ash, etc.) called precursors, under strong alkaline conditions given by the activators, can generate a chemical reaction able to create a cementitious material [1]. Geopolymers have been widely studied in the last years primarily because of their early high strength $[14,15]$, where metakaolin has attracted considerable attention because of its early resistance and good chemical resistance, among such other advantages as good fire-resistant behavior $[15,16]$. In addition, several studies highlighted that the greenhouse gas emissions generated during the geopolymer production can be around $40 \%$ lower than the ones related to Portland cement, making this material more environmentally friendly than traditional cement concrete [10]. The application of geopolymer as an alternative to cement concrete for construction and buildings is supported by well-established literature and experimental application. As for road pavements, the use of geopolymer mixtures is still under study. Metakaolin is a dehydrated form of the clay mineral kaolin, which is obtained by the calcination of this clay at temperatures of $500-800{ }^{\circ} \mathrm{C}$. As a pozzolanic material, it is considered a good substitute for ordinary Portland cement [15]. However, in economic terms, the energy needed to produce the geopolymers is still an issue. For example, in the production of sodium silicate, one of the most common activators used for the chemical reaction, the energy demand is over $30 \%$ higher if compared to that needed to obtain the feedstock for Portland cement. Furthermore, for a metakaolin-based geopolymer mixture, the total cost of production is around $80 \%$ higher than common cement concrete mixtures, mainly because of the rare supplier mines of metakaolin, which make the transportation cost high [10].

In the light of the above, the present research introduces a comparison between porous mixtures made with cement and metakaolin, to understand the effect of these materials on the design parameters, as well as on the final functional and mechanical properties in terms of Indirect Tensile Strength (ITS) and permeability. In addition, some innovative and experimental mixtures were produced and tested with the same grading distribution but using the alkali-activation process with metakaolin and waste basalt powder for the production of alternative and eco-friendly mixtures. With this, two sets of mixtures were evaluated to observe the feasibility of designing geopolymers with the methodology explained in the following sections for porous concrete mixtures.

\section{Materials and Methods}

\subsection{Methodology of Design}

For the preparation of porous samples, the PCD (Porous Concrete Design) methodology was used, which process can be consulted in [17]. This method is based on the ACI 522R-10 standard, in which the relation between the coarse aggregates and sand is eliminated, introducing the latter into the cement paste design and obtaining a mortar. Therefore, the sand amount modifies the cement and the water quantities of the mixture. The coarse aggregate quantity depends on its particle density and porosity. Meanwhile, PCD starts with a proposed porosity (AV) amount of design, sand-cement (s/c) 
and water-cement $(\mathrm{w} / \mathrm{c})$ ratio. Then the coarse aggregate weight is determined. With this, the mortar volume and weight can be calculated to finally obtain the dosages of water, cement, and sand.

The EN 1097-3 standard was used to calculate the VMA (Voids in Mineral Aggregate) of the aggregate. The test was performed twice (compacted and loose aggregates) in order to establish a parameter for the VMA content in the mixture design. According to the PCD methodology, the VMA helps to establish the material amounts, where higher VMAs provide lower amounts of coarse aggregates and add higher amounts of mortar in the design of the mixture. The opposite performance is found when lower VMA amounts are considered [17].

\subsection{Materials and Mixtures}

Limestone aggregates were employed to elaborate all the mixtures in a gradation of $5-10 \mathrm{~mm}$. For the Control mixture, Portland cement type I $42.5 \mathrm{R}$ was used, in a water to cement ratio $(\mathrm{w} / \mathrm{c})$ of 0.30 . For the experimental mixtures, metakaolin was used to partially replace the cement in amounts of $5 \%$ and $10 \%$ of the cement weight, maintaining a constant $\mathrm{w} / \mathrm{c}$ of 0.30 . The first mixture was labelled 95C-5MK and the second 90C-10MK.

In addition, three other experimental mixtures were fabricated using the alkali-activation process to produce the binder for the final concrete. No water was used and the grading distribution was kept constant using the same aforementioned design parameters. The first mixture, labelled $100 \mathrm{MK}$, was produced with $100 \%$ metakaolin as precursor, employing a blend of sodium silicate and sodium hydroxide in a ratio of 3 to 1 as activator. The chemical composition of these materials can generate the process of alkali-activation as verified in previous studies [18]. An activator-precursor (A/P) ratio of 0.87 was used because of the workability presented by the material (at a lower A/P ratio, lower workability). Furthermore, basalt powder was applied to replace $50 \%$ and $75 \%$ of metakaolin in two additional experimental mixtures named 50MK-50Bas and 25MK-75Bas, respectively. A total of six different mixtures were produced and tested. The limestone aggregate and the material properties are reported in Tables 1 and 2, respectively.

Table 1. Limestone aggregate characteristics.

\begin{tabular}{ccc}
\hline Property & Standard & Value \\
\hline Bulk density $\left(\mathrm{g} / \mathrm{cm}^{3}\right)$ & EN 1097-3 & 2.70 \\
Specific gravity & EN 1097-6 & 2.80 \\
Water absorption (\%) & EN 1097-6 & 0.90 \\
Voids in aggregate (\%) & EN 1097-3 & 49.75 \\
Gradation (mm) & EN 1097-3 & 41.24 \\
Compacted voids in aggregate (VMA) (\%) & EN 933-1 & $5-10$ \\
\hline
\end{tabular}

Table 2. Material characteristics.

\begin{tabular}{ccccccc}
\hline Property & Standard & Cement & Metakaolin & $\begin{array}{c}\text { Basalt } \\
\text { Powder }\end{array}$ & $\begin{array}{c}\text { Sodium } \\
\text { Silicate }\end{array}$ & $\begin{array}{c}\text { Sodium } \\
\text { Hydroxide }\end{array}$ \\
\hline Bulk density $\left(\mathrm{g} / \mathrm{cm}^{3}\right)$ & EN 1097-3 & 3.14 & 2.40 & 1.36 & 2.40 & 2.13 \\
Gradation $(\mathrm{mm})$ & EN 933-1 & $<0.063$ & $<0.063$ & $<0.050$ & - & - \\
\hline
\end{tabular}

Samples were designed for a diameter of $10 \mathrm{~cm}$ and $6.5 \mathrm{~cm}$ height, compacted in the Marshall device at 35 blows on the surface, in compliance with the EN 12697-30 standard. Cement mixtures were submerged under water for 28 days for curing. The geopolymer mixtures were instead placed in the oven for $12 \mathrm{~h}$ at $70{ }^{\circ} \mathrm{C}$ and then cured for 21 days at room temperature. The curing in the oven is a common procedure for geopolymer mixtures and the setting time and temperature was validated in previous researches on the same synthetic mixture $[1,18]$. 


\subsection{Geopolymer Mortar Characterization}

In order to characterize the geopolymer paste, three $4 \times 4 \times 4 \mathrm{~cm}$ cubes were cast for each mixture and tested at different curing times ( 7 and 21 days). It is worth noting that there are no specific tests or standards for geopolymers. Thus, the mechanical properties are generally analyzed by evaluating the compressive strength of cubic samples in compliance with the EN 1015-11 standard, which refers to hardened mortars. It can be seen in Figure 1 that from curing day 7 to day 21 values seemed to be constant for the mixture with 100\% metakaolin and the mixture with $50 \%$ metakaolin and $50 \%$ basalt powder, varying within $10 \mathrm{MPa}$. The mixture with $25 \%$ metakaolin and $75 \%$ basalt powder had a poor result at 21 days of curing because of the low amount of metakaolin, as basalt powder does not provide a good adherence for the aggregate particles. Overall, mixtures seemed to be cured just after 7 days. This was a further confirmation of the early strength of alkali-activate materials. Moreover, the 100MK showed a compressive strength even higher than the typical values registered for traditional Portland cement concretes after 7 days of curing. Finally, due to the difference in the performances the mixtures had because of the diverse materials and dosages employed, it was decided to test only one sample per mixture, as the objective was to observe the behaviors presented by the mixtures under the same methodology of design.

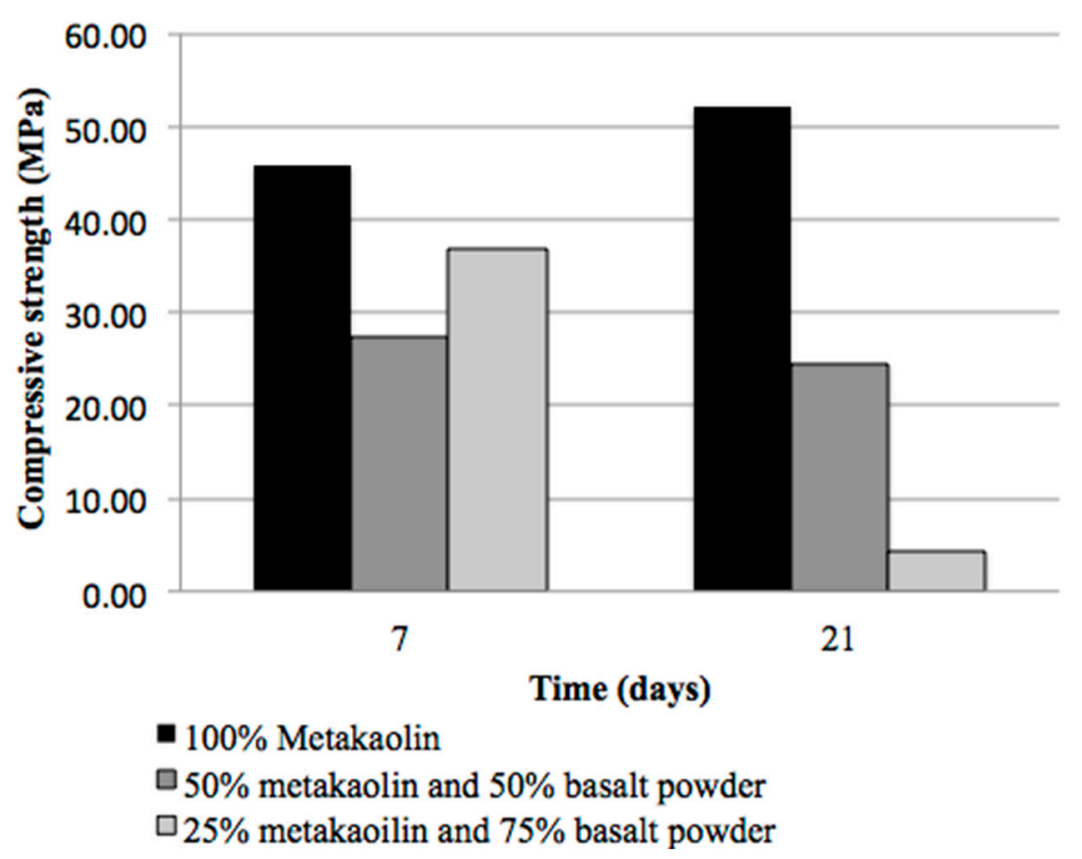

Figure 1. Compressive strength of geopolymer mixtures after different curing periods.

\subsection{Determination of the Voids in Mineral Aggregate and the Porosity of Mixtures}

Porous concrete pavements are normally designed to have a certain amount of porosity, between $15 \%$ and $30 \%$ [5-8]. Therefore, it was decided to establish a porosity target of $20 \%$ for the cement concrete mixtures designed in this investigation, as well as a VMA of $47 \%$ (in the range $41.24 \%-49.75 \%$ in Table 1), to increase the mortar amount in the mixtures, enhancing the mechanical strength. Considering that geopolymer mixtures do not have the same behavior, four different tentative mixtures were made, varying the VMA and the $\mathrm{AV}$ in order to decide the parameters for the final porous mixture design. VMAs of $41.52 \%$ and $47 \%$ and $A V s$ of $20 \%$ and $30 \%$ were combined (mixtures A, B, C, and D in Figure 2 ) to define the best combination for the geopolymer mixtures, selected as values between the parameters obtained in the VMAs from Figure 1. 
A



C

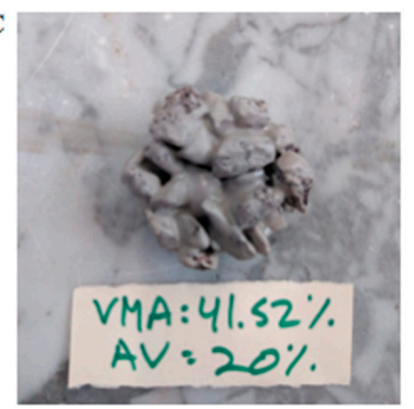

B

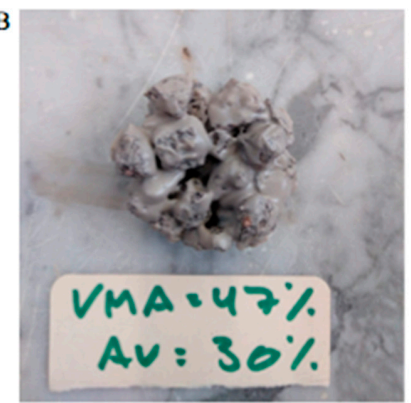

$\mathrm{D}$

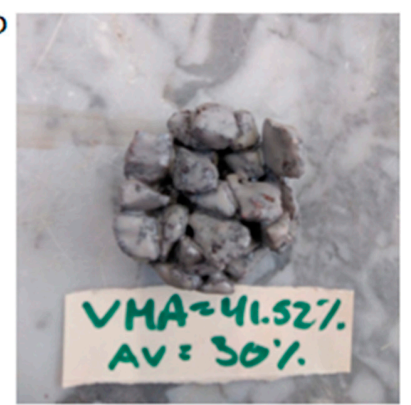

Figure 2. Four different dosages proposed for geopolymer mixtures, varying the voids in mineral aggregate (VMA) and porosity (AV), where (A) corresponds to a VMA of $47 \%$ and $\mathrm{AV}$ of $20 \%$ (highest amount of mortar); (B) to a VMA of $47 \%$ and AV of $30 \%$; (C) to a VMA of $41.52 \%$ and AV of $20 \%$; (D) to a VMA of $41.52 \%$ and $\mathrm{AV}$ of $30 \%$ (lowest amount of mortar).

As visible in Figure 2, the geopolymer paste used for mixture A, with the same design parameters adopted for the cement concrete, tended to clog the mixture completely. Therefore, for these mixtures, we considered employing opposite parameters (higher AV and lower VMA) than cement concrete, as showed by mixture D, which had the highest AV among the four mixtures. Mixture type D was selected for the final mix design of geopolymer mixtures to guarantee the presence of sufficient interconnected voids for infiltrating water. Mixtures B and C obtained a higher percentage of mortar in their designs than mixture $\mathrm{D}$ (lower than mixture $\mathrm{A}$ ). This meant that both mixtures obtained fewer interconnected voids for permeability. In fact, they were almost clogged completely, not considered to fulfill a good permeability for porous mixtures.

The behavior of the mortars for each type of mixture is presented in Figure 3: the cement tended to create mortar bridges that bound together the aggregate particles, while the geopolymer paste seemed to coat completely the aggregates.

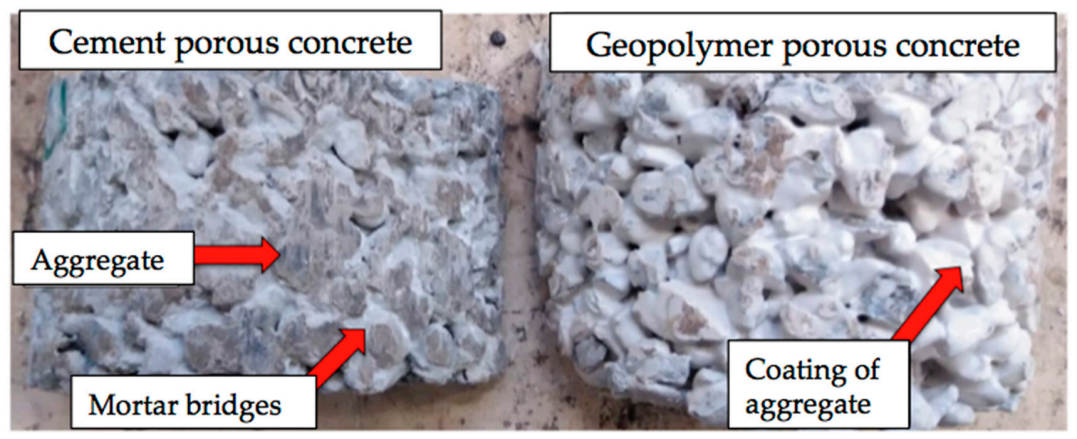

Figure 3. Mortar behavior between a cement porous concrete and a geopolymer porous concrete.

The final design parameters for all the mixtures are summarized in Table 3. 
Table 3. Mixture compositions.

\begin{tabular}{|c|c|c|c|c|c|c|c|c|c|c|}
\hline \multirow{2}{*}{ Mixture } & \multicolumn{3}{|c|}{ Cementitious Material (g) } & \multirow{2}{*}{$\begin{array}{c}\text { Agg }^{1} \\
\text { (g) }\end{array}$} & \multirow{2}{*}{$\begin{array}{l}\text { Water } \\
\text { (g) }\end{array}$} & \multirow{2}{*}{ w/c } & \multicolumn{2}{|c|}{ Activator (g) } & \multirow{2}{*}{$\mathrm{A} / \mathbf{P}^{1}$} & \multirow{2}{*}{$\begin{array}{l}\text { Porosity } \\
\text { (\%) }\end{array}$} \\
\hline & $C^{1}$ & MK $^{1}$ & Bas $^{1}$ & & & & SS $^{1}$ & $\mathrm{SH}^{1}$ & & \\
\hline Control & 237.50 & - & - & 771.80 & 80.60 & 0.30 & - & - & - & 20.00 \\
\hline $95 \mathrm{C}-5 \mathrm{MK}$ & 224.12 & 11.80 & - & 771.80 & 80.00 & 0.30 & - & - & - & 20.00 \\
\hline 90С-10MK & 210.77 & 23.42 & - & 771.80 & 79.50 & 0.30 & - & - & - & 20.00 \\
\hline 100MK & - & 77.60 & - & 855.40 & - & - & 57.20 & 19.10 & 0.87 & 30.00 \\
\hline 50MK-50Bas & - & 40.05 & 40.05 & 855.40 & - & - & 58.80 & 19.60 & 0.87 & 30.00 \\
\hline 25MK-75Bas & - & 20.33 & 60.99 & 855.40 & - & - & 59.50 & 19.80 & 0.87 & 30.00 \\
\hline
\end{tabular}

${ }_{1}^{1}$ C: cement; MK: metakaolin; Bas: basalt powder; Agg: coarse aggregate; SS: sodium silicate; SH: sodium hydroxide; A/P: Activator-Precursor ratio.

\subsection{Experimental Plan}

The experimental plan was based on the evaluation of the total porosity (volumetric property), permeability (hydraulic property), and the Indirect Tensile Strength (mechanical property) of the mixtures. In compliance with the ASTM C1688 standard, the porosity amount $(A V)$ can be calculated with the Equation (1):

$$
A V=\left(\frac{\rho_{t}-\rho}{\rho_{t}}\right) \times 100,
$$

where $\rho_{\mathrm{t}}$ corresponds to the bulk density, calculated by the sum of the total mass of the material proportions employed to elaborate the mixture in accordance to standard EN 1097-3, divided by the volume of the mold, and $\rho$ is the real density obtained from the net mass of the sample divided by the volume of the container.

The permeability of the mixtures was obtained with a falling-head permeameter adapted for laboratory uses from the Spanish NLT 327/00 standard. It consists of a 10-cm diameter methacrylate tube, placed on top of the sample, which allows the water to flow into the sample to perform the test. The tube was calibrated for a 20-cm water column. Then, employing Darcy's law, the permeability capacity can be calculated, according to Equation (2):

$$
k=\left[\frac{\left(A_{\text {sample }}\right) \times\left(h_{\text {sample }}\right)}{\left(A_{\text {tube }}\right) \times(t)}\right]\left[\ln \left(\frac{h_{1}}{h_{2}}\right)\right],
$$

where $k$ is the permeability capacity $(\mathrm{cm} / \mathrm{s}), A_{\text {sample }}$ is the area of contact of the sample, $h_{\text {sample }}$ is the height of the sample, $A_{\text {tube }}$ is the area of the tube's gap, and $t$ is the time that the water takes to flow from the highest point $h_{1}$ to the lowest point $h_{2}$.

The Indirect Tensile Strength (ITS) test was performed in order to analyze the mechanical properties of the mixtures according to the EN 12390-6 standard. This test enables an indirect assessment of the pavement behavior under traffic loads by the evaluation of the level of cohesion between aggregates, generated by the cement binder. The ITS test description, equipment, and equations used were in compliance with the EN 12390-6 and EN-12390-1 standards. Finally, the behavior of geopolymer mixtures after being exposed to water (permeability test) was measured through the ITS, as well. Once the permeability test was made, mixtures were dried at ambient temperature for 14 days to perform the ITS, evaluating one sample per mixture. A flow chart is presented in Figure 4 to summarize the experimental plan of the following research. 




Figure 4. Experimental plan flow chart.

\section{Results and Discussion}

\subsection{Porosity and Permeability}

The total porosity (AV) and permeability (k) results are shown in Figure 5.

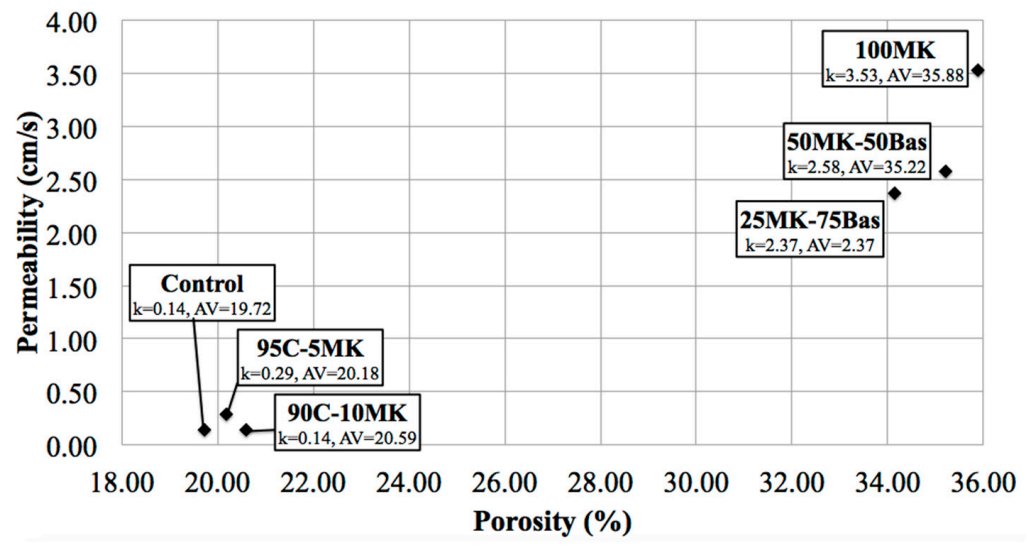

Figure 5. Porosity and permeability general results. 
It can be observed that the geopolymer mixtures achieved permeability results over $90 \%$ higher than the Control mixture because of the porosity parameter used in order to control the VMAs. If the mixtures with cement (Control, 95C-5MK, and 90C-10MK) had been designed with a higher porosity, the mortar amount would have been lower, making the adhesion between the aggregate particles poor and, therefore, weak.

In addition, the use of basalt powder in the geopolymer mixtures tended to clog the air voids in the sample, decreasing the permeability capacity. The addition of $50 \%$ of basalt powder decreased the permeability by $27 \%$, and with $75 \%$ of basalt powder the decrement was equal to $33 \%$. Nevertheless, both $\mathrm{AV}$ and permeability results were considerably high for the geopolymer mixtures with basalt powder.

In the case of replacing part of the cement with metakaolin (95C-5MK and 90C-10MK), results demonstrated that the porosity increased and permeability resulted. In this scenario, replacing $5 \%$ of cement with metakaolin doubled the permeability. However, the increase in the metakaolin amount of $10 \%$ can be considered excess, where the mortar tended to cover the aggregates more and permeability started to decrease, showing the same results as the Control mixture. It can be stated that the replacement of cement with metakaolin over $5 \%$ seemed to negatively affect the permeability of the mixture. Nevertheless, according to the National Center for Asphalt Technology, a minimum permeability of $100 \mathrm{~m} /$ day $(0.012 \mathrm{~cm} / \mathrm{s})$ is suggested for open-graded friction courses [19,20]. Therefore, all the mixtures overcame that parameter, even the Control mixture with the lowest permeability $(0.14 \mathrm{~cm} / \mathrm{s})$. In addition, the behavior of the mixtures demonstrated that at higher porosity, permeability tended to increase, a performance in compliance with some authors' results [21,22].

\subsection{Density and Indirect Tensile Strength}

The density $(\rho)$ and indirect tensile strength (IT) results are presented in Figure 6.

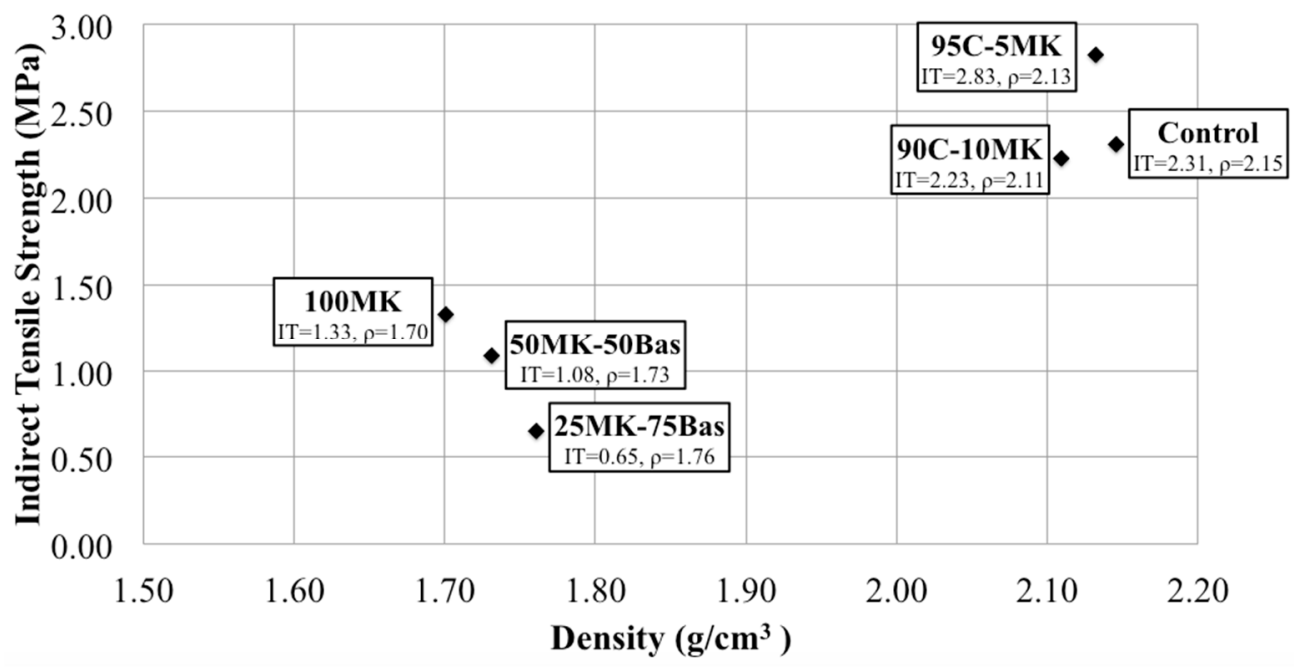

Figure 6. Indirect tensile and density general results.

Here, the geopolymer mixtures obtained lower results if compared to the mixtures with cement, because of the higher porosity. Between the geopolymer mixtures, 100MK showed the highest ITS values, and this was in line with the mechanical properties highlighted in the geopolymer paste characterization. However, in wider terms, the $100 \mathrm{MK}$ reached ITS values $42 \%$ lower than the Control mixture. Nevertheless, it can be observed that mixtures 100MK and 50MK-50Bas achieved acceptable values of ITS, over $1 \mathrm{MPa}$, despite the high porosity the sample presented.

In addition, the use of basalt powder demonstrated a weak bond between the geopolymer paste and the aggregate, as the paste became more fluent and went to the bottom of the mold. This clogged the mixture and decreased ITS: $50 \%$ of basalt powder in the mixture decreased the ITS by almost $19 \%$ if compared to mixture $100 \mathrm{MK}$. Adding basalt powder up to $75 \%$ of the cementitious material 
weight reduced the strength around $51 \%$. It was observed that the lowest cohesion between aggregate particles led to lower ITS results.

In the case of the cement mixtures, ITS results increased by $18 \%$ when replacing $5 \%$ of cement with metakaolin (95C-5MK) without a relevant variation in the density, compared to the Control mix. The ITS was reduced to almost the same values as the Control mixture when the metakaolin amount increased to $10 \%$ (90C-10MK).

Furthermore, to compare the obtained results with other experimental porous concretes, a detailed literature review was carried out. Bringing together the most recent studies on ITS in porous concrete pavements, Table 4 demonstrates the lower and higher results achieved by each author, as well as the $\mathrm{w} / \mathrm{c}$, aggregate size, and additional materials employed. ITS values range from $0.02 \mathrm{MPa}$ to 3.09 MPa. Taking this into account, all the experimental mixtures included in this research paper showed acceptable results.

Table 4. Indirect tensile results and materials employed by some authors.

\begin{tabular}{|c|c|c|c|c|c|}
\hline Author & Ref. & $\mathrm{IT}^{1}(\mathrm{MPa})$ & $w / c$ & $\operatorname{Agg}^{1}(\mathrm{~mm})$ & Note \\
\hline Torres, A. et al., 2015 & [23] & $1.09-3.09$ & 0.33 & $6.35-9.54$ & 3 compaction levels and 2 aggregate sizes (limestone) evaluated. \\
\hline Bonicelli, A. et al., 2015 & [24] & $0.02-0.21$ & $0.27-0.35$ & $3-10$ & Addition of sand. \\
\hline Rangelov, M. et al., 2016 & [5] & $1.40-2.90$ & 0.24 & 9.5 & Addition of carbon fibers. \\
\hline Adewumi, A. et al., 2016 & {$[25]$} & $0.21-1.32$ & $0.35-0.40$ & $4.50-22$ & Different mixtures of coarse aggregate, cement and w/c were used. \\
\hline Brake, N. et al., 2016 & {$[6]$} & $0.98-3.04$ & $0.27-0.30$ & 10 & $\begin{array}{c}\text { Type I polycarboxylate superplasticizer and type S viscosity } \\
\text { modifying agent were employed. }\end{array}$ \\
\hline Bonicelli, A. et al., 2016 & {$[26]$} & $1.40-2.20$ & $0.27-0.35$ & - & Monofilament polypropylene and polyethylene fibers used. \\
\hline Hsin-Lun, H. et al., 2018 & {$[27]$} & $0.5-2.1$ & 0.35 & $19-25$ & $\begin{array}{l}\text { Portland cement, and co-fired fly ash and blast-furnace slag as } \\
\text { replacement of cement were used. }\end{array}$ \\
\hline Mohd-Ibrahim, M.Y. et al., 2018 & {$[28]$} & $2.5-4.3$ & 0.34 & $4.75-12.5$ & Use of nano black rise husk ash and crushed granites. \\
\hline $\begin{array}{l}\text { Tataranni, P. and Sangiorgi, C., } \\
2019\end{array}$ & {$[18]$} & $0.48-0.60$ & - & $6.3-12.5$ & $\begin{array}{c}\text { Use of a polymeric binder, activated with sodium silicate and sodium } \\
\text { hydroxide. Synthetic and limestone aggregate. }\end{array}$ \\
\hline Alshareedah, O. et al., 2019 & [29] & $1.1-1.5$ & 0.35 & $4.75-9.5$ & Addition of cured carbon fiber composite material. \\
\hline Elizondo-Martinez, E.J. et al., 2020 & [9] & $1.62-2.75$ & 0.30 & $4-8$ & $\begin{array}{l}\text { Combination of superplasticizer, air entraining, and polypropylene } \\
\text { fibers for the highest result. }\end{array}$ \\
\hline
\end{tabular}

In addition, considering some authors obtained high ITS values by employing additives, fibers, or other additions (such as sand and certain types of ash) to improve the properties of the mixture, the results obtained in the present investigation demonstrated that the methodology of design, as well as the compaction method used, can achieve very good results, with a range between $0.65 \mathrm{MPa}$ and $2.83 \mathrm{MPa}$.

\subsection{Optimal Mixtures and Performance Requirements}

Figure 7 shows the graph proposed by Bonicelli et al. [26], showing the performance requirements for different urban uses of porous concrete pavements and locating results of the present investigation. As stated by the authors, mid-volume urban roads require ITS values over $1.9 \mathrm{MPa}$, low-volume urban roads and parking lots require instead ITS values between 1.7 and $1.9 \mathrm{MPa}$ and permeability results over $1 \mathrm{~cm} / \mathrm{s}$. ITS values between 1.5 and $1.7 \mathrm{MPa}$ and permeability over $1.5 \mathrm{~cm} / \mathrm{s}$ are recognized as suitable for bike paths, while permeability values over $2 \mathrm{~cm} / \mathrm{s}$ work better for pedestrian areas, squares, foot paths, and parks.

As seen in Figure 6, all the cement-base mixtures can be considered suitable for mid-volume urban roads because of the high mechanical properties and relatively low permeability. The geopolymer mixtures are suitable for pedestrian areas, squares, footpaths, and parks because of the high permeability capacity. However, for future research, the reduction in the design AV for geopolymer concrete might improve the final ITS of the mixtures. 




Figure 7. Performance requirements for different urban uses of porous concrete pavements according to Bonicelli et al., 2016 [26].

\subsection{Water Susceptibility of Geopolymer Mixtures}

Despite the environmental advantages that porous pavements made with geopolymers can present, the exposure of these materials to water can decrease the strength of the mixtures, as Table 5 shows. Once again, an optimization of the design parameters could decrease the porosity and so increase the VMAs and the final mechanical properties. It is worth noting that in the case of the 100MK mixture, the ITS reduction was not significant $(16.67 \%)$. For the other experimental mixtures the addition of basalt had a negative effect on the ITS reduction, probably because of the already poor cohesion between particles, which was further limited by the presence of water.

Table 5. Indirect tensile results of geopolymers before and after water exposure.

\begin{tabular}{cccc}
\hline \multirow{2}{*}{ Mixture } & $\begin{array}{c}\text { Indirect Tensile } \\
\text { Strength (MPa) }\end{array}$ & $\begin{array}{c}\text { Indirect Tensile Strength after } \\
\text { Exposure to Water (MPa) }\end{array}$ & Strength Reduction (\%) \\
\hline 100MK & 1.33 & 1.10 & 16.67 \\
50MK-50BAS & 1.08 & 0.65 & 40.13 \\
25MK-75BAS & 0.65 & 0.45 & 31.37 \\
\hline
\end{tabular}

\section{Conclusions}

Cement production has a big environmental impact and, consequently, alternative materials are being studied to replace it in pavements.

The present research shows a comparison of the functional and mechanical properties of different porous concretes produced with different amounts of metakaolin and alternative geopolymer porous mixtures containing metakaolin and basalt powder.

Based on the discussed results, the following conclusions can be stated:

- Replacing 5\% of cement with metakaolin increases both the ITS and the permeability, but a substitution of $10 \%$ of cement with metakaolin reduces both the properties.

- Cement base mixtures (only with reductions of $5 \%$ or $10 \%$ ) show very high ITS values and acceptable porosity if compared to the geopolymer ones (100\% metakaolin).

- A design porosity of $20 \%$ is considered low for the geopolymer mixtures, where, because of the behavior of the paste material, the sample tends to clog. Meanwhile, a design porosity of $30 \%$ causes an excessive AV in the material that negatively affects the ITS.

- The increase in the amount of basalt powder in the mixture lowers the mechanical properties of the sample, both the compressive strength of the mortar cubes and the ITS of the porous samples. 
- According to the results, for geopolymer porous pavements, an amount of $50 \%$ or lower of basalt powder in the mixture is recommended to maintain an average mechanical-permeability relation. The amount will depend on the use the pavement is going to have. A high amount can decrease these results considerably.

- The mechanical properties of geopolymer mixtures with basalt are strongly affected when exposed to water. As the main purpose of porous pavements is to infiltrate water through their structure, adjustments in the design parameters (such as lower porosity and higher VMA) are needed to reduce the water susceptibility.

- Considering the results obtained with the dosages evaluated, geopolymer mixtures are suitable for pavements with low load, like pedestrian areas, which can comprise a large area in a city, and cement use can be decreased. They also prevent runoff during rain events.

- Cement-based mixtures, according to the results of the present investigation, can be considered for use in mid-volume urban roads (secondary streets), which represent a high percentage of pavement in a city, decreasing some amount of cement and increasing the permeable capacity of the soil, especially during rain events.

- Both cement mixtures with metakaolin and mixtures with geopolymer paste represent good alternatives for sustainable pavements, reducing the use of cement.

Author Contributions: Conceptualization, E.-J.E.-M. and P.T.; methodology, E.-J.E.-M., P.T., J.R.-H. and D.C.-F.; software, E.-J.E.-M.; validation, P.T., J.R.-H. and D.C.-F.; investigation, E.-J.E.-M.; resources, P.T.; writing-original draft preparation, E.-J.E.-M.; writing-review and editing, P.T., J.R.-H. and D.C.-F.; supervision, P.T. All authors have read and agreed to the published version of the manuscript.

Funding: This research received no external funding.

Acknowledgments: The authors would like to thank the DICAM Department of the University of Bologna for providing the materials and facilities to make this investigation.

Conflicts of Interest: The authors declare no conflict of interest.

\section{References}

1. Tataranni, P. Recycled Waste Powders for Alkali-Activated Paving Blocks for Urban Pavements: A Full Laboratory Characterization. Infrastructures 2019, 4, 73. [CrossRef]

2. Sinha, K.C.; Bullock, D.; Hendrickson, C.T.; Levinson, H.S.; Lyles, R.W.; Radwan, A.E.; Li, Z. Development of Transportation Engineering Research, Education, and Practice in a Changing Civil Engineering World. J. Transp. Eng. 2002, 128, 301-313. [CrossRef]

3. Rodriguez-Hernandez, J.; Fernández-Barrera, A.H.; Andrés-Valeri, V.C.A.; Vega-Zamanillo, A.; Castro-Fresno, D. Relationship between Urban Runoff Pollutant and Catchment Characteristics. J. Irrig. Drain. Eng. 2013, 139, 833-840. [CrossRef]

4. Elizondo-Martínez, E.; Andrés-Valeri, V.; Jato-Espino, D.; Rodriguez-Hernandez, J. Review of porous concrete as multifunctional and sustainable pavement. J. Build. Eng. 2020, 27, 100967. [CrossRef]

5. Rangelov, M.; Nassiri, S.; Haselbach, L.; Englund, K. Using carbon fiber composites for reinforcing pervious concrete. Constr. Build. Mater. 2016, 126, 875-885. [CrossRef]

6. Brake, N.A.; Allahdadi, H.; Adam, F. Flexural strength and fracture size effects of pervious concrete. Constr. Build. Mater. 2016, 113, 536-543. [CrossRef]

7. Giustozzi, F. Polymer-modified pervious concrete for durable and sustainable transportation infrastructures. Constr. Build. Mater. 2016, 111, 502-512. [CrossRef]

8. Khankhaje, E.; Salim, M.R.; Mirza, J.; Salmiati; Hussin, M.W.; Khan, R.; Rafieizonooz, M. Properties of quiet pervious concrete containing oil palm kernel shell and cockleshell. Appl. Acoust. 2017, 122, 113-120. [CrossRef] 
9. Elizondo-Martínez, E.; Andrés-Valeri, V.; Rodríguez-Hernádez, J.; Sangiorgi, C. Selection of Additives and Fibers for Improving the Mechanical and Safety Properties of Porous Concrete Pavements through Multi-Criteria Decision-Making Analysis. Sustainability 2020, 12, 2392. [CrossRef]

10. Nguyen, L.; Moseson, A.J.; Farnam, Y.; Spatari, S. Effects of composition and transportation logistics on environmental, energy and cost metrics for the production of alternative cementitious binders. J. Clean. Prod. 2018, 185, 628-645. [CrossRef]

11. Jato-Espino, D.; Lizasoain-Arteaga, E. Life cycle assessment of construction materials: Analysis of environmental impacts and recommendations of eco-efficient management practices. In Handbook of Environmental Materials Management; Hussain, C.M., Ed.; Springer: Cham, Switzerland, 2018.

12. Jang, J.G.; Ahn, Y.B.; Souri, H.; Lee, H.K. A novel eco-friendly porous concrete fabricated with coal ash and geopolymeric binder: Heavy metal leaching characteristics and compressive strength. Constr. Build. Mater. 2015, 79, 173-181. [CrossRef]

13. Chen, X.; Guo, Y.; Ding, S.; Zhang, H.; Xia, F.; Wang, J.; Zhou, M. Utilization of red mud in geopolymer-based pervious concrete with function of adsorption of heavy metal ions. J. Clean. Prod. 2018, 207, 789-800. [CrossRef]

14. Bouguermouh, K.; Bouzidi, N.; Mahtout, L.; Pérez-Villarejo, L.; Martínez-Cartas, M.L. Effect of acid attack on microstructure and composition of metakaolin-based geopolymers: The role of alkaline activator. J. Non. Cryst. Solids 2017, 463, 128-137. [CrossRef]

15. Mohammed, A.; Salih, A.; Raof, H. Vipulanandan Constitutive Models to Predict the Rheological Properties and Stress-Strain Behaviour of Cement Grouts Modified with Metakaolin. J. Test. Eval. 2020, 48. [CrossRef]

16. Busari, A.; Dahunsi, B.; Akinmusuru, J. Sustainable concrete for rigid pavement construction using de-hydroxylated Kaolinitic clay: Mechanical and microstructural properties. Constr. Build. Mater. 2019, 211, 408-415. [CrossRef]

17. Elizondo-Martinez, E.J.; Andres-Valeri, V.C.; Rodriguez-Hernandez, J.; Castro-Fresno, D. Proposal of a New Porous Concrete Dosage Methodology for Pavements. Materials 2019, 12, 3100. [CrossRef]

18. Tataranni, P.; Sangiorgi, C. Synthetic aggregates for the production of innovative low impact porous layers for urban pavements. Infrastructures 2019, 4, 48. [CrossRef]

19. Alvarez, A.E.; Martin, A.E.; Estakhri, C.K.; Button, J.W.; Glover, C.J.; Jung, S.H. Synthesis of Current Practice on the Design, Construction, and Maintenance of Porous Friction Courses; Technical Report No. FHWA/TX-06/0-5262-1; Texas Department of Transportation Research and Technology Implementation Office: Austin, TX, USA; Texas Transportation Institute at the Texas A\&M University System: College Station, TX, USA, 2006; p. 76.

20. Mallick, R.B.; Kandhal, P.S.; Cooley, L.A.; Watson, D.E. Design, Construction and Performance of New Generation Open-Graded Friction Courses; NCAT Report No. 2000-01; National Center for Asphalt Technology (NCAT), Auburn University: Auburn, AL, USA, 2000.

21. Praticòo, F.G.; Moro, A. Permeability and Volumetrics of Porous Asphalt Concrete. A Theoretical and Experimental Investigation. Road Mater. Pavement Des. 2007, 8, 799-817. [CrossRef]

22. Yasarer, H.; Najjar, Y. Development of void prediction models for Kansas concrete mixes used in PCC pavement. Procedia Comput. Sci. 2012, 8, 473-478. [CrossRef]

23. Torres, A.; Hu, J.; Ramos, A. The effect of the cementitious paste thickness on the performance of pervious concrete. Constr. Build. Mater. 2015, 95, 850-859. [CrossRef]

24. Bonicelli, A.; Giustozzi, F.; Crispino, M. Experimental study on the effects of fine sand addition on differentially compacted pervious concrete. Constr. Build. Mater. 2015, 91, 102-110. [CrossRef]

25. Adewumi, A.A.; Owolabi, T.O.; Alade, I.O.; Olatunji, S.O. Estimation of physical, mechanical and hydrological properties of permeable concrete using computational intelligence approach. Appl. Soft Comput. J. 2016, 42, 342-350. [CrossRef]

26. Bonicelli, A.; Arguelles, G.M.; Pumarejo, L.G.F. Improving Pervious Concrete Pavements for Achieving More Sustainable Urban Roads. Procedia Eng. 2016, 161, 1568-1573. [CrossRef]

27. Ho, H.L.; Huang, R.; Hwang, L.C.; Lin, W.T.; Hsu, H.M. Waste-based pervious concrete for climate-resilient pavements. Materials 2018, 11, 900. [CrossRef] 
28. Ibrahim, M.Y.M.; Ramadhansyah, P.J.; Rosli, H.M.; Ibrahim, M.H.W. Mechanical performance of porous concrete pavement containing nano black rice husk ash. IOP Conf. Ser. Mater. Sci. Eng. 2018, 290, 012050. [CrossRef]

29. AlShareedah, O.; Nassiri, S.; Chen, Z.; Englund, K.; Li, H.; Fakron, O. Field performance evaluation of pervious concrete pavement reinforced with novel discrete reinforcement. Case Stud. Constr. Mater. 2019, 10, e00231. [CrossRef]



(C) 2020 by the authors. Licensee MDPI, Basel, Switzerland. This article is an open access article distributed under the terms and conditions of the Creative Commons Attribution (CC BY) license (http://creativecommons.org/licenses/by/4.0/). 